\section{Hepatic and splenic sonographic and sonoelastographic findings in pulmonary arterial hypertension}

\author{
Illhan Hekimsoy ${ }^{1}$, Burçin Kibar Öztürk², Hatice Soner Kemal ${ }^{3}$, Meral Kayıkçıoğlu4, \\ Ömer Faruk Dadaș ${ }^{5}$, Gülgün Kavukçu', Mehmet Nurullah Orman ${ }^{5}$, Sanem Nalbantgil', \\ Sadık Tamsel ${ }^{1}$, Hakan Kültürsay ${ }^{4}$, Süha Süreyya Özbek ${ }^{1}$ \\ ${ }^{1}$ Department of Radiology, Ege University Faculty of Medicine, Izmir; ${ }^{2}$ Department of \\ Radiology, İzmir Tepecik Training and Research Hospital, Izmir, Turkey; ${ }^{3}$ Department of \\ Cardiology, Near East University Faculty of Medicine, Nicosia, Cyprus; ${ }^{4}$ Department of \\ Cardiology, Ege University Faculty of Medicine, Izmir; ${ }^{5}$ Department of Biostatistics and \\ Medical Informatics, Ege University Faculty of Medicine, Izmir, Turkey
}

Purpose: The aim of this study was to evaluate the associations of sonographic and sonoelastographic parameters with clinical cardiac parameters, as well as to assess their value in predicting survival in patients with pulmonary arterial hypertension (PAH).

Methods: Thirty-six patients with PAH and normal liver function were prospectively enrolled in this prospective study along with 26 healthy controls, all of whom underwent ultrasound and point shear wave elastography examinations. Additionally, the portal vein pulsatility index (PVPI), inferior vena cava collapsibility index, and clinical cardiac variables were obtained in PAH patients. The values of hepatic $\left(\mathrm{LV}_{s}\right)$ and splenic shear wave velocity $\left(\mathrm{SV}_{\mathrm{s}}\right)$ were compared between PAH patients and controls. The relationships between all sonographic and clinical parameters in the PAH patients were analyzed. Furthermore, their prognostic value in predicting survival was investigated.

Results: $\mathrm{LV}_{\mathrm{s}}$ values in PAH patients (median, $1.62 \mathrm{~m} / \mathrm{s}$ ) were significantly higher than in controls (median, $0.99 \mathrm{~m} / \mathrm{s}$ ), while no significant difference was observed in $\mathrm{SV}_{\mathrm{s}}$ values. Patients with higher grades of tricuspid regurgitation (TR) had significantly different values of PVPI ( $P=0.010)$ and sonoelastographic parameters $\left(\mathrm{P}<0.001\right.$ for $\mathrm{LV}_{\mathrm{s}}$ and $\mathrm{P}=0.004$ for $\mathrm{SV}_{\mathrm{s}}$ ) compared to those with less severe TR. Tricuspid annular plane systolic excursion values were the only investigated parameter found to be associated with survival (hazard ratio, $0.814 ; 95 \%$ confidence interval, 0.694 to $0.954 ; \mathrm{P}=0.011$ ).

Conclusion: Our results demonstrated a direct association between cardiac congestion (i.e., the severity of TR) and liver stiffness, which should be kept in mind during the assessment of fibrosis in patients with $\mathrm{PAH}$.

Keywords: Congestion; Pulmonary arterial hypertension; Shear wave elastography; Elasticity imaging techniques; Stiffness

e-ultrasonography.org Ultrasonography 40(2), April 2021

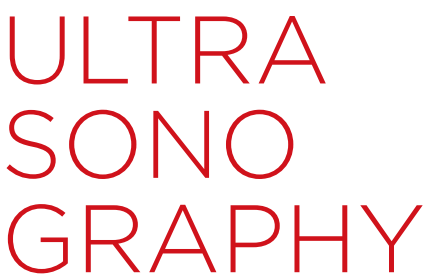

\section{ORIGINAL ARTICLE}

https://doi.org/10.14366/usg.20076 pISSN: 2288-5919 • elSSN: 2288-5943 Ultrasonography 2021;40:281-288

Received: May 24, 2020

Revised: June 28, 2020

Accepted: July 7, 2020

Correspondence to: Illhan Hekimsoy, MD, Department of Radiology, Ege University Faculty of Medicine, Ízmir 35100, Turkey

Tel. +90-(232)-244-1292

Fax. +90-(232)-342-0001

E-mail: ihekimsoy@hotmail.com, ihekimsoy@gmail.com

This is an Open Access article distributed under the terms of the Creative Commons Attribution NonCommercial License (http://creativecommons.org/ licenses/by-nc/4.0/) which permits unrestricted noncommercial use distribution and reproduction in any medium, provided the original work is properly cited.

Copyright @ 2021 Korean Society of Ultrasound in Medicine (KSUM)

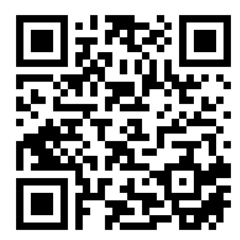

How to cite this article:

Hekimsoy İ, Öztürk BK, Kemal HS, Kayıkçıŏlu M, Dadaș ÖF, Kavukçu G, et al. Hepatic and splenic sonographic and sonoelastographic findings in pulmonary arterial hypertension. Ultrasonography. 2021 Apr;40(2):281-288. 


\section{Introduction}

In recent decades, several novel, non-invasive techniques have been developed to assess the degree of liver fibrosis, such as analyses of liver stiffness (LS) by elastography. Different applications of shear wave elastography (SWE) have been introduced for this purpose. Transient elastography (TE; Fibroscan, Echosens, France) was the first technique to be used and validated in this field. Numerous studies have been conducted to determine its usefulness and accuracy for the diagnosis of liver fibrosis in patients with chronic liver disease [1-4]. More recently, new SWE techniques have been implemented in medical ultrasound (US) systems, thereby allowing sonoelastographic exams to be performed in combination with real-time US examinations to quantify tissue stiffness [5]. Point shear wave elastography (pSWE) works by high-intensity US waves causing localized tissue displacement in a small region of interest (ROI) depending on the characteristics of the related tissue, resulting in the generation of shear waves that are detected by the US scanner with additional software capability, thereby indirectly quantifying $L S$, as the shear wave velocity (SWV) is proportional to the tissue elasticity [6-8]. The correlation between $L S$ and fibrosis is well known, but is also influenced by several other pathologies, such as fatty infiltration, inflammation, cholestasis, congestion, and the patient's food/liquid intake before the exam $[7,9]$. The effects of these confounding factors have been documented by many studies using $T E$, and their influence on different SWE techniques is still being explored in different clinical processes and patient groups [10-13]. Moreover, as pSWE is a newer technique than TE, the number of studies on the effect of congestion as a confounding factor on PSWE in pathologic processes is still limited, and none have been conducted for pulmonary arterial hypertension (PAH) to the best of our knowledge [14-26].

In this study, we hypothesized that liver and spleen stiffness measured via PSWE would be directly related to the degree of congestion and severity of PAH, and thus might be used as additional useful parameters for management and prediction of the prognosis. Hence, we aimed to investigate the effects of cardiac congestion on sonoelastographic parameters in patients with PAH, a vitally important pathology that has not been studied using sonoelastography before. In this context, we assessed the relationship of sonoelastographic parameters with routine clinical cardiac parameters, as well as the long-term survival rates of PAH patients in our study group.

\section{Materials and Methods}

\section{Study Design and Patient Population}

This prospective, single-center, cross-sectional, single-blind study was approved by the Institutional Review Board of our hospital. All patients enrolled in this study provided written informed consent prior to their inclusion. During a 20-month period between 2013 and 2015, 36 newly diagnosed PAH patients with normal liver function tests and negative serological markers of acute or chronic liver diseases were included in the study, together with 26 healthy controls with no known hepatic pathology and a similar age and sex distribution. In addition to the initial clinical and sonographic studies related to the study, the current health status of the patients with PAH was checked in February 2020. The exclusion criteria of our study were as follows: (1) patients with known or detected hepatic diseases, including alcoholic hepatitis, alcoholic or non-alcoholic fatty liver disease, acute or chronic viral hepatitis, or hematologic diseases; (2) patients who declined to participate; (3) inadequate patient cooperation that compromised the sonoelastographic examination; (4) patients with open wounds or bandages that hampered mobility of the US probe at the level of the costal arches; (5) presence of hemorrhage, infarction, or a space-occupying lesion that hindered the sonoelastographic evaluation within the lateral part of the hepatic or splenic parenchyma; (6) severe orthopnea resulting in elevation of the head of the bed by more than $30^{\circ}$; and (7) patients who were treated or currently receiving medications for PAH.

Initially, the patients with PAH underwent a clinical assessment for the diagnosis of PAH using cardiac parameters, including echocardiographic variables (systolic pulmonary artery pressure [SPAP], tricuspid regurgitation velocity [TRV], tricuspid annular plane systolic excursion [TAPSE]), cardiac catheterization parameters (mean pulmonary artery pressure [mPAP], pulmonary artery wedge pressure [PAWP]), liver function tests, serological markers of acute or chronic liver diseases, and New York Heart Association (NYHA) functional class or 6-minute-walk distance test results. They were then referred to the Department of Radiology.

Blinded to the clinical and laboratory data, a single radiologist with more than 5 years of experience with pSWE performed B-mode standard US scanning and pSWE in the same session, using a US device (Acuson S2000) with Virtual Touch tissue quantification software (Siemens Medical Solutions USA, Inc., Mountain View, CA, USA). A C6-1 HD convex probe with a frequency range between 1.0 and $6.0 \mathrm{MHz}$ was routinely used for the exams. After fasting for at least 6 hours, all patients in the PAH and the control groups underwent hepatic and splenic assessments with B-mode and Doppler US prior to PSWE measurements. During the sonographic 
examinations of all patients and healthy controls, the size of the liver and spleen, the echogenicity and homogeneity of the hepatic and splenic parenchyma, and the presence of space-occupying lesions were evaluated and noted. In patients with $\mathrm{PAH}$, further sonographic analysis yielded the portal vein pulsatility index (PVPI) and inferior vena cava collapsibility index (IVCCI) values, which were calculated as described before $[27,28]$. In the sonoelastographic evaluation, pSWE measurements in the right hepatic lobe (segments 5 or 6) (Fig. 1) and lower half of the spleen were obtained through intercostal spaces, where the parenchyma was homogenous and devoid of any vessels or surrounding structures. The ROI was placed at least $2 \mathrm{~cm}$ deep to the organ capsule while the supine lying patient was suspending his/her breath in the mid-respiration phase. The SWV was calculated by measuring maximal lateral displacement and the duration required for the peak displacement. The results were demonstrated in units of meters per second $(\mathrm{m} / \mathrm{s})$. Using the onboard software of the US device, we calculated the median, average, and interquartile range (IQR) ratio (IQR/median, IQRR) using at least 10 valid pSWV measurements in the liver of all patients and healthy controls. The calculated median value (liver shear wave velocity value $\left[\mathrm{LV}_{\mathrm{s}}\right]$ ) of at least 10 consecutive hepatic SWV measurements was accepted as representative of $L S$ in a given patient only if the IQRR of all valid measurements was less than $30 \%$. Thus, the $\mathrm{LV}_{\mathrm{s}}$ values of four PAH patients and a healthy control were excluded from the statistical analysis. Likewise, the representative splenic SWV values $\left(\mathrm{SV}_{\mathrm{s}}\right)$ were determined by calculating the median value of at least 10 valid splenic measurements from each patient and healthy control. The $S V_{s}$ values of four patients and a healthy control were not included in the statistical analysis because the IQRR values exceeded $30 \%$. Additionally, patients with PAH were divided into two groups

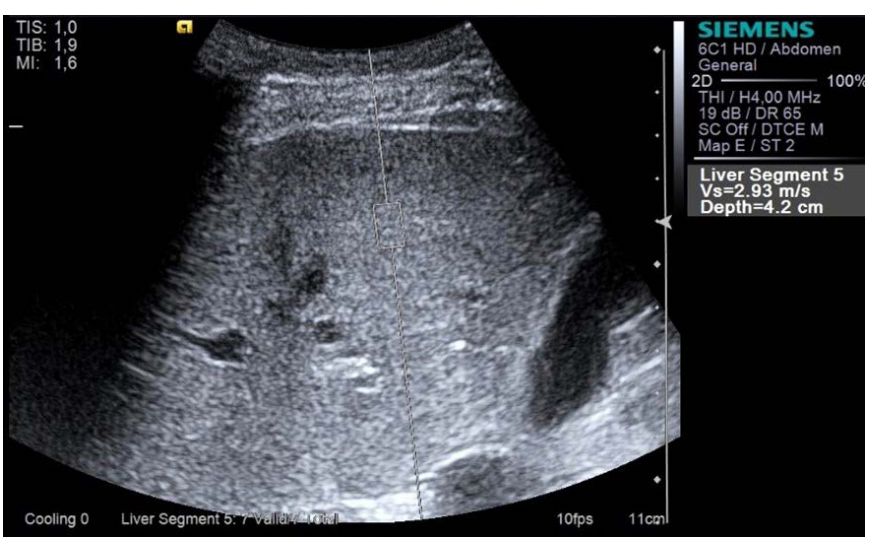

Fig. 1. An example image of point shear wave elastography assessment in the right liver lobe in a 36-year-old woman with pulmonary arterial hypertension. The region of interest was placed at a depth of $4.2 \mathrm{~cm}$ from the skin surface, and a shear wave velocity of $2.93 \mathrm{~m} / \mathrm{s}$ was obtained. to analyze possible associations between the severity of tricuspid regurgitation (TR) and the values of PVPI, IVCCl, $\mathrm{LV}_{\mathrm{s}}$ and $\mathrm{SV}_{\mathrm{s}}$. Group 1 consisted of PAH patients with grade 1 or $2 \mathrm{TR}$, while the patients with higher grades of TR (grade 3 or 4) comprised group 2.

To investigate the presence of any associations of sonographic and clinical laboratory parameters with the survival rates of the patients with PAH, these patients' medical records were scrutinized in February 2020, at least 65 months after their sonographic assessment (in addition to any other available communication records), in order to evaluate relationships between the study parameters and survival.

\section{Statistical Analysis}

Statistical analysis was performed using SPSS version 25.0 (IBM Corp., Armonk, NY, USA) for Windows (Microsoft Corp., Redmond, WA, USA). A P-value of less than 0.05 was regarded as indicating statistical significance. Descriptive statistical analysis was performed for the study sample, and the data were expressed as mean values with standard deviations or median values with interquartile ranges, as appropriate. The independent Student $t$ test and chi-square test were used to determine the significance of differences between the patient and control groups in terms of age, sex, and body mass index (BMI). $\mathrm{LV}_{s}$ and $\mathrm{SV}_{\mathrm{s}}$ in the PAH patients were compared using the independent Student $t$ test and the Mann-Whitney $U$ test depending on whether the data had a parametric or nonparametric distribution. Receiver operating characteristic analysis was conducted to detect the most favorable cut-off value for $\mathrm{LV}_{\mathrm{s}}$. The correlations between clinical parameters and PVPI, IVCCI, $\mathrm{LV}_{\mathrm{s}}$ and $\mathrm{SV}_{\mathrm{s}}$ in the patient and control groups were tested using the non-parametric Spearman correlation coefficient. The Kaplan-Meier method was performed to estimate the survival rate of patients with $\mathrm{PAH}$, and Cox proportional hazards regression analysis was used to investigate the parameters affecting survival.

\section{Results}

Thirty-six patients with PAH and 26 healthy volunteers were enrolled in our study. All healthy volunteers and patients were eligible for the pSWE examination. Of the 36 included patients, 22 (61\%) were women. The mean age of the patient group was $50.56 \pm 17.01$ years, with an age range of 19 to 75 . Of the 26 healthy volunteers enrolled in the study, 17 (65.4\%) were women, with ages between 27 and 79 years (mean, $54.35 \pm 12.26$ years). The mean BMl in the patient and control groups was $25.64 \pm 6.29 \mathrm{~kg} / \mathrm{m}^{2}$ and $25.11 \pm 3.49 \mathrm{~kg} / \mathrm{m}^{2}$, respectively. The average age, sex, and BMI were not significantly different between the patient and control groups. The clinical characteristics of the patient group are presented in Table 1. 
The liver and splenic parenchyma were homogeneous, with normal echogenicity in both groups. Neither the patient nor the control group had space-occupying lesions within the liver or spleen. The number of patients with hepatomegaly was not remarkably different between the groups, while splenomegaly was significantly more common in the patient group (Table 2). Quantitative sonographic parameters (PVPI and IVCCI) could be obtained in 33 of the 36 patients with PAH. The average PVPI and IVCCI values were $0.46 \pm 0.26$ (mean \pm standard deviation [SD]) and $0.38 \pm 0.26$ $($ mean $\pm S D)$, respectively. Both IVCCI $\left(r_{\circ}=0.35, P=0.049\right)$ and PVPI $\left(r_{\circ}\right.$ $=-0.45, P=0.009$ ) were significantly correlated with TAPSE values. On further analysis, higher PVPI values were detected in patients

Table 1. Clinical characteristics of the patient group

\begin{tabular}{lc}
\hline \multicolumn{1}{c}{ Characteristic } & Total $(\mathrm{n}=36)$ \\
\hline Clinical factor & \\
Age (year) & $50.56 \pm 17.01$ \\
Female sex & $22(61.1)$ \\
BMI (kg/m ${ }^{2}$ ) & $25.64 \pm 6.29$ \\
NYHA class I/II & $4(11.1) / 15(41.7)$ \\
NYHA class II/IV & $16(44.4) / 1(2.8)$ \\
6-Minute walk distance (m) & $299.4 \pm 131.6$ \\
PAH cause & \\
Idiopathic and familial PAH & $12(33.3)$ \\
Connective tissue disease-associated PAH & $5(13.9)$ \\
Congenital heart disease-associated PAH & $10(27.8)$ \\
Chronic thromboembolic pulmonary hypertension & $9(25.0)$ \\
Pulmonary artery catheterization & \\
Mean pulmonary artery pressure (mm Hg) & $44.1 \pm 17.5$ \\
Pulmonary artery wedge pressure $(\mathrm{mm}$ Hg) & $9.7 \pm 5.8$
\end{tabular}

Values are presented as mean \pm standard deviation or number (\%).

BMI, body mass index; NYHA, New York Heart Association; PAH, pulmonary arterial hypertension.

Table 2. B-mode ultrasound findings, and sonoelastographic parameters

\begin{tabular}{lccc}
\hline \multicolumn{1}{c}{ Variable } & PAH & Control & P-value \\
\hline $\begin{array}{l}\text { B-mode ultrasound data } \\
\text { Hepatomegaly }\end{array}$ & $5(13.9)$ & 0 & 0.068 \\
$\quad$ Splenomegaly & $14(38.9)$ & $2(7.7)$ & 0.005 \\
$\begin{array}{l}\text { Sonoelastographic } \\
\text { parameters }\end{array}$ & & & \\
$\mathrm{LV}_{\mathrm{s}}(\mathrm{m} / \mathrm{s})$ & $1.62(1.10-2.53)$ & $0.99(0.86-1.11)$ & $<0.001$ \\
$\mathrm{SV}_{\mathrm{s}}(\mathrm{m} / \mathrm{s})$ & $3.27(2.75-3.52)$ & $3.21(2.88-3.44)$ & 0.784 \\
\hline
\end{tabular}

Values are presented as number (\%) or median (interquartile range).

$\mathrm{LV}_{\mathrm{s}}$ liver shear wave velocity; $\mathrm{PAH}$, pulmonary arterial hypertension; $\mathrm{SV}_{\mathrm{s}}$ splenic shear wave velocity. with more severe TR, yet no association could be found pertaining to IVCCI (Table 3).

For both $\mathrm{LV}_{\mathrm{s}}$ and $\mathrm{SV}_{\mathrm{s}}$ acceptable measurements (IQRR<30\%) were achieved in 32 of the 36 patients with PAH (88.9\%), and in 25 of the 26 healthy controls (96.2\%). LV (median, $1.62 \mathrm{~m} / \mathrm{s} ; \mathrm{IQR}, 1.10$ to $2.53 \mathrm{~m} / \mathrm{s} ; \mathrm{n}=32$ ) in the patient group was significantly higher than in the control group (median, $0.99 \mathrm{~m} / \mathrm{s}$; IQR, 0.86 to $1.11 \mathrm{~m} / \mathrm{s} ; n=25$ ), while no such difference was observed in terms of $\mathrm{SV}_{\mathrm{s}}$ (median, 3.27 $\mathrm{m} / \mathrm{s} ; \mathrm{IQR}, 2.75$ to $3.52 \mathrm{~m} / \mathrm{s} ; \mathrm{n}=32$ and median, $3.21 \mathrm{~m} / \mathrm{s} ; \mathrm{IQR}, 2.88$ to $3.44 \mathrm{~m} / \mathrm{s} ; n=25$, respectively) (Table 2). The optimal cut-off value for $\mathrm{LV}_{\mathrm{s}}$ to differentiate the patients from the healthy controls was $1.18 \mathrm{~m} / \mathrm{s}$, and the area under the curve, sensitivity, and specificity values for this cut-off were calculated as $0.82,69 \%$, and $96 \%$, respectively.

Within the patient group, TR severity was significantly correlated with $\mathrm{LV}_{\mathrm{s}}$ and $\mathrm{SV}_{\mathrm{s}}$ values. The patients in group 2 (i.e., PAH patients with TR severity of grade 3 or 4) demonstrated higher $\mathrm{LV}_{\mathrm{s}}$ and $\mathrm{SV}_{\mathrm{s}}$ than those in group 1 (TR severity grades of 1 or 2) (Table 3). Moreover, the $\mathrm{LV}_{s}$ value $\left(\mathrm{r}_{\mathrm{o}}=0.52, \mathrm{P}=0.003\right)$ was significantly correlated with PVPI. In contrast, no correlations were found between SWV values and clinical parameters, including other echocardiographic variables (SPAP, TRV, TAPSE), catheterization parameters (mPAP, PAWP), NYHA functional class, or 6-minute-walk distance test results.

Among the basic demographic (age, sex, and BMI), clinical (NYHA functional class), quantitative sonographic, sonoelastographic (LV and $\mathrm{SV}_{\mathrm{s}}$ ), echocardiographic (SPAP, TRV, TAPSE), and catheterization (mPAP, PAWP) parameters, TAPSE was the only variable found to have a significant association with survival in patients with PAH (hazard ratio, $0.814 ; 95 \%$ confidence interval, 0.694 to $0.954 ; P=0.011)$. The 6-month, $1-, 3$ - and 5 -year survival rates

Table 3. Quantitative sonographic and sonoelastographic parameters of the patient group according to the severity of TR

\begin{tabular}{lccr}
\hline \multirow{2}{*}{ Variable } & \multicolumn{2}{c}{ Grade of TR } & \multirow{2}{*}{ P-value } \\
\cline { 2 - 3 } & 1 or $2(\mathrm{n}=14)$ & 3 or $4(\mathrm{n}=19)$ & \\
\hline $\begin{array}{l}\text { Quantitative sonographic } \\
\text { parameters }\end{array}$ & $0.31 \pm 0.13$ & $0.58 \pm 0.27$ & 0.010 \\
$\mathrm{PVPI}$ & $0.45(0.03-0.90)$ & $0.27(0.05-0.86)$ & 0.090 \\
IVCCI & & & \\
$\begin{array}{l}\text { Sonoelastographic } \\
\text { parameters }\end{array}$ & $1.09(0.77-4.38)$ & $2.30(1.10-4.04)$ & $<0.001$ \\
$\mathrm{LV}_{\mathrm{s}}(\mathrm{m} / \mathrm{s})$ & $2.69(2.42-3.90)$ & $3.44(2.92-4.58)$ & 0.004 \\
$\mathrm{SV}_{\mathrm{s}}(\mathrm{m} / \mathrm{s})$ & &
\end{tabular}

Values are presented as mean \pm standard deviation or median (range),

TR, tricuspid regurgitation; PVPI, portal vein pulsatility index; IVCCI, inferior vena cava collapsibility index; $\mathrm{LV}_{\mathrm{s}}$ liver shear wave velocity value; $\mathrm{SV}_{\mathrm{s}}$, splenic shear wave velocity value. 


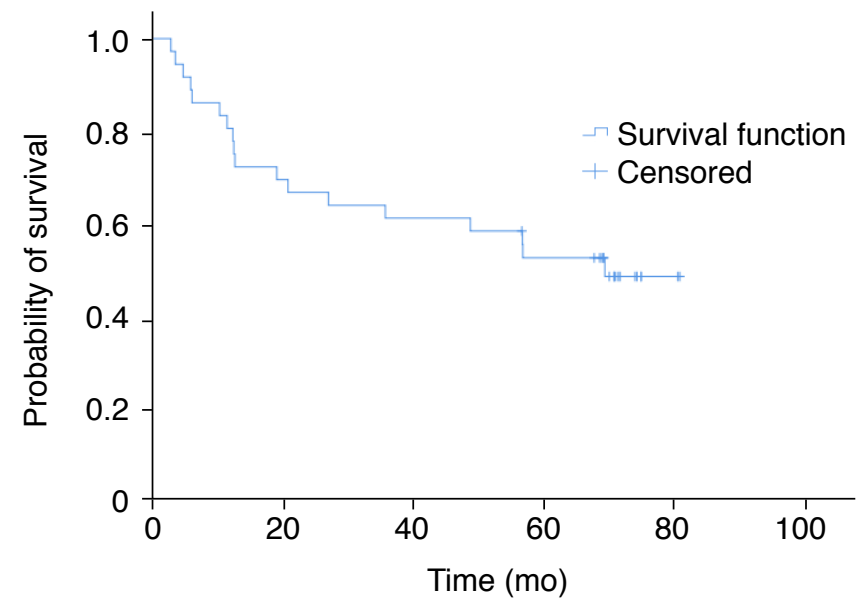

Fig. 2. Kaplan-Meier estimates of survival for pulmonary arterial hypertension (PAH) patients. The mean survival time of PAH patients was calculated to be $51.9 \pm 5.4$ months $(95 \%$ confidence interval, 41.4 to 62.5 months).

of the patients with PAH were $86.1 \%, 81 \%, 61.1 \%$, and $53 \%$, respectively. The mean survival time of PAH patients was calculated to be $51.9 \pm 5.4$ months (Fig. 2).

\section{Discussion}

The quantitative sonographic parameters that were investigated in this study (i.e., IVCCI and PVPI), demonstrated a weak positive and moderate negative correlation with an echocardiographic variable (TAPSE), respectively. These findings are in accordance with those of Styczynski et al. [29], who found a substantial relationship between PVPI and TAPSE values via a logistic regression model in patients with heart failure. However, we found no significant correlation between quantitative sonographic and cardiac catheterization parameters such as MPAP and PAWP in the present study, as opposed to the results of Stawicki et al. [30], who reported a weak negative correlation between IVCCI and mPAP values in critically ill patients, the majority of whom were under mechanical ventilation. The differences between these results may be related to the impact of mechanical ventilation, which may have affected hemodynamics and IVCCI values [27]. Nonetheless, we detected significantly higher PVPI values in patients with more severe grades of TR, in accordance with the work of Shih et al. [31]. In summary, consistent with a great deal of previously reported results, our findings suggest that quantitative sonographic variables such as IVCCI and PVPI may be of clinical use in the diagnosis and follow-up of PAH patients.

The $\mathrm{LV}_{\mathrm{s}}$ value was found to be potentially valuable in the followup process of patients with $\mathrm{PAH}$, as a significant relationship was found between the degree of congestion and LS. Statistically, LV had better specificity than sensitivity in discriminating patients with PAH from the control cases. Since patients with normal liver function tests were included in the study sample, we believe that these results primarily reflect the effect of congestion on LS. Correspondingly, PVPI was correlated with $\mathrm{LV}_{s}$. Furthermore, both of the sonoelastographic parameters differed significantly between the two groups of patients defined based on the severity of TR. Some previous studies including patients with congestion stemming from reasons other than PAH evaluated the direct effect of congestion on LS by eliminating other factors and reported that LS was increased by congestion, similarly to the results of our study $[16,17,26,32]$. Therefore, radiologists who want to detect liver fibrosis via PSWE should be cautious when interpreting $L S$ in patients with cardiac congestion, as cardiac congestion may cause overestimation of the severity or even a false-positive diagnosis of fibrosis.

The follow-up study of our patient group yielded similar survival rates to those reported in previous research. The 5 -year survival rate of PAH patients in our cohort was within the range reported by Koudstaal et al. [33]. Our analysis of sonographic, sonoelastographic, and clinical cardiac variables demonstrated that only TAPSE was associated with survival in patients with PAH. This result aligns with those of other studies in the literature that have reported this parameter to be a prognostic factor in PAH [34-37].

There are a few limitations of our study. First, the number of cases was relatively small. Hence, further studies with larger study samples are needed to determine whether PSWE is a useful, noninvasive procedure that is helpful for the diagnosis and prediction of survival in PAH. Second, patients with normal liver function tests were enrolled in our study to determine the direct effect of congestion on LS. However, liver function tests have relatively low accuracy in identifying mild fibrosis, and liver biopsy is the gold standard method for detecting liver fibrosis [38]. Since we did not perform liver biopsy, mild fibrosis might have been overlooked in our PAH patients. Biopsy was not clinically justified in our patient population, as they were newly diagnosed with normal liver function tests together with negative serological markers of acute or chronic liver diseases and had no known or detected liver disease. Furthermore, we assumed that any possible mild hepatic fibrosis that had not caused any abnormalities in liver function tests would not result in significant changes in hepatosplenic stiffness values that would affect our results $[7,39]$. Third, the sonographic and sonoelastographic examinations could not be performed in a completely blinded manner with regard to whether an individual was a PAH patient or a control, since the clinical status of the examined PAH patients was readily indicative of their disease in most cases. However, meticulous objectivity was applied in obtaining US data from all cases in the study. Fourth, although for obtaining 
survival rates of PAH patients, we evaluated the latest medical records and the most recently obtained information from patients, it was difficult to eliminate causes of death other than PAH without a detailed autopsy. However, given the high and well-known risk of mortality caused by PAH, we believe that PAH was at least indirectly responsible for most of our patients' deaths [40]. Furthermore, our finding that TAPSE was a predictor of an increased mortality rate, which is in line with previous literature on the topic, provides support that our methodology of evaluating survival rates was, to a great extent, acceptable.

In conclusion, our results demonstrated the direct influence of cardiac congestion on LS in patients with PAH. Therefore, currently available sonoelastographic techniques for the assessment of liver fibrosis cannot be applied to patients with PAH. However, our analysis suggests that this technique may be helpful for discriminating PAH patients with severe TR from milder cases. However, no correlations were detected between sonoelastographic and clinical cardiac parameters, and TAPSE was the only investigated parameter found to be associated with survival. In light of our findings, we suggest further evaluation of PSWE as a possibly valuable test for the follow-up of PAH patients and as a prognostic predictor for PAH by future studies with a larger patient population.

ORCID: Illhan Hekimsoy: https://orcid.org/0000-0001-5768-1239; Burçin Kibar Öztürk: https://orcid.org/0000-0003-3135-7857; Hatice Soner Kemal: https://orcid.org/0000-00029616-3386; Meral Kayıkçığlu: https://orcid.org/0000-0003-3692-5227; Ömer Faruk Dadaș: https://orcid.org/0000-0003-2692-3762; Gülgün Kavukçu: https://orcid.org/0000-00016866-7256; Mehmet Nurullah Orman: https://orcid.org/0000-0003-3544-9329; Sanem Nalbantgil: https://orcid.org/0000-0002-9798-9796; Sadık Tamsel: https://orcid.org/00000001-8749-782X; Hakan Kültürsay: https://orcid.org/0000-0002-0304-8849; Süha Süreyya Özbek: https://orcid.org/0000-0002-3351-4150

\section{Author Contributions}

Conceptualization: Hekimsoy İ, Öztürk BK, Kayıkçıŏlu M, Özbek SS. Data acquisition: Hekimsoy İ, Öztürk BK, Kemal HS, Kayıkçıŏlu M, Kavukçu G, Nalbantgil S, Tamsel S, Kültürsay H, Özbek SS. Data analysis or interpretation: Hekimsoy I, Dadaș ÖF, Orman MN, Özbek SS. Drafting of the manusript: Hekimsoy I, Dadaș ÖF, Orman MN, Özbek SS. Critical revision of the manuscript: Hekimsoy I, Öztürk BK, Kemal HS, Kayıkçıoğlu M, Kavukçu G, Nalbantgil S, Tamsel $S$, Kültürsay $H$, Özbek SS. Approval of the final revision of the manuscript: all authors.

\section{Conflict of Interest}

No potential conflict of interest relevant to this article was reported.

\section{References}

1. Castera L, Vergniol J, Foucher J, Le Bail B, Chanteloup E, Haaser M, et al. Prospective comparison of transient elastography, Fibrotest, APRI, and liver biopsy for the assessment of fibrosis in chronic hepatitis C. Gastroenterology 2005;128:343-350.

2. Sporea I, Sirli R, Deleanu A, Tudora A, Curescu M, Cornianu M, et al. Comparison of the liver stiffness measurement by transient elastography with the liver biopsy. World I Gastroenterol 2008; 14:6513-6517.

3. Sporea I, Sirli RL, Deleanu A, Iulia R, Tudora A, Dan I, et al. What did we learn from the first 3,459 cases of liver stiffness measurement by transient elastography (FibroScan $®$ ) ? Ultraschall Med 2011;32:40-45.

4. Vergniol J, Foucher J, Terrebonne E, Bernard PH, le Bail B,

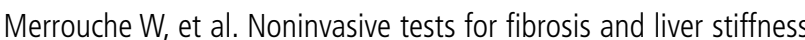
predict 5-year outcomes of patients with chronic hepatitis C. Gastroenterology 2011;140:1970-1979.

5. Friedrich-Rust M, Wunder $\mathrm{K}$, Kriener $\mathrm{S}$, Sotoudeh F, Richter $\mathrm{S}$, Bojunga J, et al. Liver fibrosis in viral hepatitis: noninvasive assessment with acoustic radiation force impulse imaging versus transient elastography. Radiology 2009;252:595-604.

6. Sporea I, Bota S, Gradinaru-Tascau 0, Sirli R, Popescu A. Comparative study between two point shear wave elastographic techniques: acoustic radiation force impulse (ARFI) elastography and ElastPQ. Med Ultrason 2014;16:309-314.

7. Dietrich CF, Bamber J, Berzigotti A, Bota S, Cantisani V, Castera L, et al. EFSUMB guidelines and recommendations on the clinical use of liver ultrasound elastography, update 2017 (long version). Ultraschall Med 2017;38:e16-e47.

8. Nightingale K, Soo MS, Nightingale R, Trahey G. Acoustic radiation force impulse imaging: in vivo demonstration of clinical feasibility. Ultrasound Med Biol 2002;28:227-235.

9. Byenfeldt M, Elvin A, Fransson P. On patient related factors and their impact on ultrasound-based shear wave elastography of the liver. Ultrasound Med Biol 2018;44:1606-1615.

10. Arena U, Vizzutti F, Abraldes JG, Corti G, Stasi C, Moscarella S, et al. Reliability of transient elastography for the diagnosis of advanced fibrosis in chronic hepatitis C. Gut 2008;57:1288-1293.

11. Chen SH, Li YF, Lai HC, Kao JT, Peng CY, Chuang PH, et al. Effects of patient factors on noninvasive liver stiffness measurement using acoustic radiation force impulse elastography in patients with chronic hepatitis C. BMC Gastroenterol 2012;12:105.

12. Berzigotti A, De Gottardi A, Vukotic R, Siramolpiwat S, Abraldes JG, Garcia-Pagan JC, et al. Effect of meal ingestion on liver stiffness in patients with cirrhosis and portal hypertension. PLoS One 2013;8:e58742.

13. Nishikawa $T$, Hashimoto $S$, Kawabe $N$, Harata $M$, Nitta $Y$, Murao $M$, et al. Factors correlating with acoustic radiation force impulse 
elastography in chronic hepatitis C. World J Gastroenterol 2014;20:1289-1297.

14. Kutty SS, Peng Q, Danford DA, Fletcher SE, Perry D, Talmon GA, et al. Increased hepatic stiffness as consequence of high hepatic afterload in the Fontan circulation: a vascular Doppler and elastography study. Hepatology 2014;59:251-260.

15. Melero-Ferrer JL, Osa-Saez A, Buendia-Fuentes F, Ballesta-Cunat A, Flors $L$, Rodriguez-Serrano $M$, et al. Fontan circulation in adult patients: acoustic radiation force impulse elastography as a useful tool for liver assessment. World I Pediatr Congenit Heart Surg 2014;5:365-371.

16. Potthoff A, Schettler A, Attia D, Schlue J, Schmitto JD, Fegbeutel C, et al. Liver stiffness measurements and short-term survival after left ventricular assist device implantation: a pilot study. J Heart Lung Transplant 2015;34:1586-1594.

17. DiPaola FW, Schumacher KR, Goldberg CS, Friedland-Little J, Parameswaran A, Dillman JR. Effect of Fontan operation on liver stiffness in children with single ventricle physiology. Eur Radiol 2017;27:2434-2442.

18. Mebus S, Nagdyman N, Kugel J, Zachoval R, Braun SL, Haverkamper $G$, et al. Non-invasive assessment of liver changes in Eisenmenger patients. Int J Cardiol 2017;249:140-144.

19. Di Maria MV, Silverman L, Younoszai AK, Meyers ML, Capocelli KE, Narkewicz MR. Acoustic radiation force impulse of the liver after Fontan operation: correlation with cardiopulmonary exercise test. Congenit Heart Dis 2018;13:444-449.

20. Horvat N, Rocha MS, Chagas AL, Oliveira BC, Pacheco MP, Binotto $M A$, et al. Multimodality screening of hepatic nodules in patients with congenital heart disease after Fontan procedure: role of ultrasound, ARFI elastography, CT, and MRI. AJR Am J Roentgenol 2018;211:1212-1220.

21. Buendia-Fuentes F, Melero-Ferrer JL, Plaza-Lopez D, Rueda-Soriano J, Osa-Saez A, Aguero J, et al. Noninvasive liver assessment in adult patients with Fontan circulation using acoustic radiation force impulse elastography and hepatic magnetic resonance imaging. World J Pediatr Congenit Heart Surg 2018;9:22-30.

22. Ackerman T, Geerts A, Van Vlierberghe H, De Backer J, Francois K. Hepatic changes in the Fontan circulation: identification of liver dysfunction and an attempt to streamline follow-up screening. Pediatr Cardiol 2018;39:1604-1613.

23. Nagdyman N, Mebus S, Kugel J, Zachoval R, Clevert DA, Braun $S L$, et al. Non-invasive assessment of liver alterations in Senning and Mustard patients. Cardiovasc Diagn Ther 2019;9(Suppl 2):S198-S208.

24. Omote K, Nagai T, Asakawa N, Kamiya K, Tokuda Y, Aikawa T, et al. Impact of admission liver stiffness on long-term clinical outcomes in patients with acute decompensated heart failure. Heart Vessels 2019;34:984-991.

25. Demirtas AO, Koc AS, Sumbul HE, Koca H, Icen YK, Demirtas D, et al. Liver stiffness obtained by ElastPQ ultrasound shear wave elastography independently determines mean right atrial pressure. Abdom Radiol (NY) 2019;44:3030-3039.

26. Koca $H$, Koc AS, Sumbul HE, Koc M. Liver stiffness increases in patients with severe pericardial effusion, especially in the presence of cardiac tamponade. Med Ultrason 2020;22:133-138.

27. Kircher BJ, Himelman RB, Schiller NB. Noninvasive estimation of right atrial pressure from the inspiratory collapse of the inferior vena cava. Am J Cardiol 1990;66:493-496.

28. Gallix BP, Taourel P, Dauzat M, Bruel JM, Lafortune M. Flow pulsatility in the portal venous system: a study of Doppler sonography in healthy adults. AJR Am J Roentgenol 1997;169:141144.

29. Styczynski G, Milewska A, Marczewska M, Sobieraj P, Sobczynska M, Dabrowski M, et al. Echocardiographic correlates of abnormal liver tests in patients with exacerbation of chronic heart failure. J Am Soc Echocardiogr 2016;29:132-139.

30. Stawicki SP, Papadimos TJ, Bahner DP, Evans DC, Jones C. Correlations between pulmonary artery pressures and inferior vena cava collapsibility in critically ill surgical patients: an exploratory study. Int J Crit IIIn Inj Sci 2016;6:194-199.

31. Shih CY, Yang SS, Hu JT, Lin CL, Lai YC, Chang CW. Portal vein pulsatility index is a more important indicator than congestion index in the clinical evaluation of right heart function. World J Gastroenterol 2006;12:768-771.

32. Wang HK, Lai YC, Tseng HS, Lee RC, Loong CC, Lin NC, et al. Hepatic venous congestion after living donor liver transplantation: quantitative assessment of liver stiffness using shear wave elastography: a case report. Transplant Proc 2012;44:814-816.

33. Koudstaal T, Boomars KA, Kool M. Pulmonary arterial hypertension and chronic thromboembolic pulmonary hypertension: an immunological perspective. J Clin Med 2020;9:561.

34. Forfia PR, Fisher MR, Mathai SC, Housten-Harris T, Hemnes AR, Borlaug BA, et al. Tricuspid annular displacement predicts survival in pulmonary hypertension. Am J Respir Crit Care Med 2006; 174:1034-1041.

35. Mazurek JA, Vaidya A, Mathai SC, Roberts JD, Forfia PR. Followup tricuspid annular plane systolic excursion predicts survival in pulmonary arterial hypertension. Pulm Circ 2017;7:361-371.

36. Wright LM, Dwyer N, Celermajer D, Kritharides L, Marwick TH. Follow-up of pulmonary hypertension with echocardiography. JACC Cardiovasc Imaging 2016;9:733-746.

37. Siddiqui I, Rajagopal S, Brucker A, Chiswell K, Christopher B, Alenezi F, et al. Clinical and echocardiographic predictors of outcomes in patients with pulmonary hypertension. Am J Cardiol 2018;122:872-878.

38. Park HS, Choe WH, Han HS, Yu MH, Kim YJ, Jung SI, et al. Assessing significant fibrosis using imaging-based elastography in chronic hepatitis B patients: pilot study. World I Gastroenterol 2019;25:3256-3267. 
39. Bota S, Sporea I, Peck-Radosavljevic M, Sirli R, Tanaka H, lijima $H$, et al. The influence of aminotransferase levels on liver stiffness assessed by acoustic radiation force impulse elastography: a retrospective multicentre study. Dig Liver Dis 2013;45:762-768.
40. Tonelli AR, Arelli V, Minai OA, Newman J, Bair N, Heresi GA, et al. Causes and circumstances of death in pulmonary arterial hypertension. Am J Respir Crit Care Med 2013;188:365-369. 